\title{
nature
}

13 November 1997 Volume 390 Issue no 6656

Strategy needs disciplines

The UK government will soon reveal its thinking about universities. There are critical challenges in science to be tackled by researchers, funders and advocates acting more coherently within disciplinary contexts.

T he forthcoming White Paper from the British government on the future of higher education will prove inadequate if it bases its recommendations on university research only on the advice of the Dearing committee. That committee, established to stimulate thinking on higher education, skated over some of the critical problems affecting the research community. Worryingly, there is little sign that the Labour government's Department for Education and Employment (DFEE) will be thinking any more deeply about research.

The financial problems are severe: the evidence of inadequate equipment is widely accepted. The Dearing committee's partial panacea - a substantial "revolving loan fund" — has already proved to be a mirage. The government must either find hundreds of millions of pounds or send a clear message that it is unable to do so for the foreseeable future. And, sooner rather than later, the DFEE (which funds university staff and infrastructure) and the Office of Science and Technology (funding the research councils) must together clarify criteria for funding that in effect signal the intended scale and diversity of the research community. Only then will the research and higher education community be able to plan effectively, and only then can tough decisions reshaping the research base be taken sensibly.

As was clear from a meeting about these issues last week, organized by Nature, many of those working with the university system are frustrated by the absence of a clear national strategy and also by the feeling that advocacy on their behalf is ineffective. Progress will best be made from the principle that strategy and advocacy are most powerful when directed at or from scientific disciplines. An individual's scientific identity and motivation are forged within a discipline, and teaching is sought and given on a disciplinary basis - hence the continuing importance of disciplinary departments. Research strategies of nations and of employers requires analysis by disciplines, whereas international networks develop within disciplinary frameworks. Although multidisciplinary approaches are required more and more, those tend to address specific problems on which strong disciplinary skills are brought to bear.

Future planning needs to work with that grain, bestowing more effectively the rewards of peer-reviewed excellence given by funding councils to universities and by research councils, industry and charities to those who deliver the goods: researchers. The underlying goal for the government's funding bodies must be to maximize research productivity and the ability of departments and research groups to act as intellectual and educational entrepreneurs.

That necessitates streamlining and cross-referencing peer assessment across government agencies to minimize its burden and also more directly rewarding departments for their progress - even at the expense of some of the discretion of vice-chancellors over money from funding councils. University departments have been through three research assessment exercises within the past decade and have responded to research councils and industry as a result of national foresight exercises. Their research staff are now of unprecedentedly high calibre. Time, then, to set about diminishing the practical burdens of accountability, and extending the periods over which excellent scientists are guaranteed funding. And good working relationships and transparency between researchers and department heads will be ever more essential if departments are to act effectively.

What of advocacy to government? Universities have diverse agendas internally and externally, and will find it hard to improve their collective representation. Messages from Save British Science and the much more powerful Royal Society will inevitably be blunted by their need to represent all disciplines. Biologists have their case readymade: molecular biology is of immediate relevance to national wealth and health, while the powerful UK pharmaceutical companies are acting coherently as a lobbying force for their discipline. Given the competition for funds, the need for the lobbying skills of the Institute of Physics and the Royal Society of Chemistry and associated industries has never been greater. The pressure of advocacy will increasingly fall on them, while departments adapt or die.

\section{Make radio polluters pay}

\section{Governments need to do more to curb pollution of astronomically essential radio bands.}

$\mathrm{n}$ the film Contact, extraterrestrial life announced its presence to Jodie Foster using radio signals and the universal language of mathematics. It would be nice to think that the public, who flocked to see the film, is now sensitized to the cultural importance of radioastronomy, and might be dismayed to learn of its threatened obliteration by mobile telephones.

Pollution of radiofrequencies is perpetrated by commercial satellite companies and permitted by national governments. Their meeting point is the International Telecommunication Union (ITU), a United Nations body which allocates the radiospectrum and controls radio regulations. The ITU accommodates commercial needs by ignoring one of its own rules: "harmful interference should not be caused to radioastronomy". An unwritten qualification — "provided that it does not cost too much" — dominates decisions. Thus the ITU has agreed toothless and non-mandatory guidelines for regulating the quality of satellite transmissions (see page 103). These are insufficient to stop overspill emissions.

In the same way that they enforce regulations to protect rare habitats and designated areas of scientific interest, national governments should respect their obligations to radioastronomy. They should instruct their ITU delegates - and the ITU is only as good as its delegates - to make no concessions to industrial lobbies that risk pollution of radio bandwidths of scientific importance. Yet they do not.

Individual governments also have power outside the ITU because they are responsible for issuing national licences. They should reject pending licence applications from Iridium, which wants to operate a multisatellite mobile telephone system with no guaranteed protection for radioastronomy frequencies. The customers of Iridium, and similar companies, must be forced in this way to pay for nonpolluting systems. 